International Mathematical Forum, 1, 2006, no. 25, 1227 - 1232

\title{
Homotopy Method for Optimum Performance of Multistage Rockets
}

\author{
M.A.Sharaf \\ Department of Astronomy, Faculty of Science, King Abdul Aziz University ,Jeddah ,Saudi Arabia
}

\begin{abstract}
In this paper, an iterative method of second order of convergence for optimum performance of multistage rockets is developed using homotopy continuation technique. The method does not need any priori knowledge of the initial guess, a property which avoids the critical situations between divergent to very slow convergent solutions, that may exist in the application of other numerical methods depending on initial guess.. The accuracy of the method is at least of $\mathrm{O}\left(10^{-20}\right)$, a sufficient accuracy that secures very accurate determination of the performance
\end{abstract}

\section{Introduction}

Propellant calculations based on the physical properties of available fuel (Cornelisse, et al.,1979 ; Logsdon ,1998) show that the energy levels required to place satellites in orbit are not possible for single -stage rockets. In order to over-come this problem the technique of staging has been adopted .Because the final velocity of each stage of a rocket just before jettisoned becomes the initial velocity of the next stage, it is possible to attain orbital speeds with relatively low-energy propellant-oxidizer combinations. The problem is thus reduced to constraint minimization problem by which the best over all stage weights to reach a specified injection velocity could be obtained.

The equation resulting from this minimization problem is very highly transcendental and could be solved by iterative methods, which in turn need: (a) initial guess, (b) an iterative scheme. In fact, these two points are not separated from each other, but there is a full agreement that, even accurate iterative schemes are extremely sensitive to initial guess. Moreover, in many cases the initial guess may lead to drastic situation between divergent and very slow convergent solutions.

In the field of numerical analysis, very powerful techniques have been devoted [Allgower andGeorg, 1990] to solve transcendental equations without any priori knowledge of the initial guess. These techniques are known as homotopy continuation methods . These methods ,first applied to deterministic orbit determination in NASA [Vallado,1997].Also the method was employed at the Goddard Space Flight Center to support preliminary orbit determination using tracking data from both tracking and data Relay satellite system and from traditional ground -based tracking stations[Montenbruck and Gill, 2000]. Recently [Sharaf and Sharaf, 2003], the method was first applied to the universal initial value problem of space dynamics .

Due to the urgent need for accurate determination of optimum performance of multistage rocket because of its important role in space mission, the present paper is devoted to 
develop an iterative method of second order of convergence for solving optimum performance of multistage rocket using homotopy continuation technique. The method does not need any priori knowledge of the initial guess, a property which avoids the critical situations between divergent to very slow convergent solutions, that may exist in the application of other numerical methods depending on initial guess. The accuracy of the method is at least of $\mathrm{O}\left(10^{-20}\right)$,a sufficient accuracy that secures very accurate performance determination.

\section{Performance of multistage rockets}

\subsection{Notations}

- $\mathrm{g}$ : Acceleration due gravity (assumed constant)

- $\mathrm{I}_{\mathrm{sp}, \mathrm{r}}$ : Specific impulse of the propellant of the rth. stage(=the thrust of a bound of propellant multiplied by the number of seconds required to burn it)

- $\mathrm{W}_{\mathrm{b}, \mathrm{r}}$ : Initial weight before burning of the rth. stage

- $\mathrm{W}_{\mathrm{a}, \mathrm{r}}$ : The weight after burning of the rth. stage

- $\mathrm{W}_{\mathrm{p}, \mathrm{r}}$ : Propellant weight contained in the rth. stage

- $\mathrm{W}_{\mathrm{s}, \mathrm{r}}$ : Structural weight of the rth. stage

- $\mathrm{W}_{\mathrm{a}, \mathrm{p}}$ : The payload weight

- $\mathrm{R}_{\mathrm{r}}$ : The ratio between the weights before and after burning of the rth. stage

- $\sigma_{\mathrm{r}}$ : The structure factor of the rth. stage

\subsection{Optimum performance}

Optimum performance of multistage rocket of $\mathrm{n}$ stages is:

1-To determine the values of $R_{i}$ for all stages $i=1,2, \cdots, n$ to attain the required final velocity $\mathrm{v}$ for placing space vehicle into an orbit

2-Determine the structure weights $\mathrm{W}_{\mathrm{s}, \mathrm{i}}$ for all stages $\mathrm{i}=1,2, \cdots, \mathrm{n}$ 
3-Determine the propellant weights $\mathrm{W}_{\mathrm{p}, \mathrm{i}}$ for all stages $\mathrm{i}=1,2, \cdots, \mathrm{n}$

This could be obtained by solving the constraint optimization equation:

$$
\mathrm{M}=\sum_{\mathrm{i}=1}^{\mathrm{n}} \log \mathrm{R}_{\mathrm{i}}+\log \left[1-\sigma_{\mathrm{i}}\right]-\log \left[1-\mathrm{R}_{\mathrm{i}} \sigma_{\mathrm{i}}\right]+\mu\left(\mathrm{v}-\sum_{\mathrm{i}=1}^{\mathrm{n}} \mathrm{g} \mathrm{I}_{\mathrm{sp}, \mathrm{i}} \log \mathrm{R}_{\mathrm{i}}\right)
$$

where $\mu$ is the unknown Lagrange's multiplier

\section{Homotopy Continuation Method for Solving $Y(x)=0$}

Suppose one wishes to obtain a solution of a single non-linear equation in one variable $\mathrm{x}$ ( say)

$$
\mathrm{Y}(\mathrm{x})=0,
$$

where $\quad \mathrm{Y}: \mathbf{R} \rightarrow \mathbf{R}$ is a mapping which, for our application assumed to be smooth that is , a map has as many continuous derivatives as requires. Let us consider the situation in which no priori knowledge concerning the zero point of $Y$ is available. Since we assume that such a priori know-ledge is not available, then any of the iterative methods will often fail to calculate the zero $\overline{\mathrm{x}}$, because poor starting value is likely to be chosen. As a possible remedy, one defines a homotopy or deformation $\mathrm{H}: \mathbf{R} \times \mathbf{R} \rightarrow \mathbf{R}$ such that

$$
\mathrm{H}(\mathrm{x}, 1)=\mathrm{Q}(\mathrm{x}) \quad ; \quad \mathrm{H}(\mathrm{x}, 0)=\mathrm{Y}(\mathrm{x}) \quad,
$$

where $\mathrm{Q}: \mathrm{R} \rightarrow \mathbf{R}$ is a ( trivial) smooth map having known zero point and $\mathrm{H}$ is also smooth . Typically, one may choose a convex

$$
\mathrm{H}(\mathrm{x}, \lambda)=\lambda \quad \mathrm{Q}(\mathrm{x})+(1-\lambda) \mathrm{Y}(\mathrm{x})
$$

and attempt to trace an implicitly defined curve $\Phi(\mathrm{z}) \in \mathrm{H}^{-1}(0) \quad$ from a starting point $\left(\mathrm{x}_{1}, 1\right)$ to a solution point $(\overline{\mathrm{x}}, 0)$.If this succeeds, then a zero point $\overline{\mathrm{x}}$ of $\mathrm{Y}$ is obtained. The curve $\Phi(\mathrm{z}) \in \mathrm{H}^{-1}(0)$ can be traced numerically if it is parameterized with respect to the parameter $\lambda$, then the classical embedding methods can be applied [Allgower and Georg, 1990]

\section{Computational Developments}

\section{1 . Embedding methods}


The basic idea of the embedding methods referred to at the end of Section 3 is explained in the following algorithm for tracing the curve $\Phi(z) \in \mathrm{H}^{-1}(0)$ from, say $\lambda=1$ to $\lambda=0$

\subsubsection{Computational Algorithm 1}

$\Delta$ Purpose : To solve $\mathrm{Y}(\mathrm{x})=0$ by embedding method .

$\Delta$ Input :

(1) The function $\mathrm{Q}(\mathrm{x})$ with defined root $\mathrm{x}_{1}$ such that $\mathrm{H}\left(\mathrm{x}_{1}, 1\right)=0$,

(2) positive integer $\mathrm{m}$.

$\Delta$ Out put : Solution $\mathrm{x}$ of $\mathrm{Y}(\mathrm{x})=0$.

$\Delta$ Computational Sequence :

1. Set $\mathrm{x}=\mathrm{x}_{1}, \lambda=(\mathrm{m}-1) / \mathrm{m}, \Delta \lambda=1 / \mathrm{m}$.

2. For $i:=1$ to $m$ do

begin

Solve $\mathrm{H}(\mathrm{y}, \lambda)=\lambda \mathrm{Q}(\mathrm{y})+(1-\lambda) \mathrm{Y}(\mathrm{y})=0$ iteratively for $\mathrm{y}$

using $\mathrm{x}$ as starting value .

$\mathrm{x}=\mathrm{y}$

$\lambda=\lambda-\Delta \lambda$

End

\section{4..2 Computational algorithm 2}

$\Delta$ Purpose: To compute the optimum performance of multistage rocket of $n$ stages using homotopy method

$\Delta$ Input: $\mathrm{n}, \mathrm{v}, \mathrm{m}, \mathrm{g}, \mathrm{W}_{\mathrm{b}, 1}, \mathrm{I}_{\mathrm{sp}, \mathrm{i}}, \sigma_{\mathrm{i}} ; \mathrm{i}=1,2, \cdots, \mathrm{n}$

\section{$\Delta$ Computational steps:}

1- Solve, $\mathrm{F}\left(\mu\left(=\mathrm{v}-\sum_{\mathrm{i}=1}^{\mathrm{n}} \mathrm{g} \mathrm{I}_{\mathrm{spi}} \ln \left(\frac{\mu \mathrm{g} \mathrm{I}_{\mathrm{spi}}-1}{\mu \mathrm{g} \sigma_{\mathrm{i}} \mathrm{I}_{\mathrm{spi}}}\right)=0\right.\right.$ for, $\mu$ by using computational algorithm 1

2- $\mathrm{R}_{\mathrm{i}}=-\frac{1-\mu \mathrm{g} \mathrm{I}_{\mathrm{sp}, \mathrm{i}}}{\mu \mathrm{g} \sigma_{\mathrm{i}} \mathrm{I}_{\mathrm{sp}, \mathrm{i}}} ; \mathrm{i}=1,2, \cdots, \mathrm{n}$

3- $\mathrm{W}_{\mathrm{p}, 1}=\mathrm{W}_{\mathrm{b}, 1}\left(\mathrm{R}_{1}-1\right) / \mathrm{R}_{1}$ 
Homotopy Method

4- $\mathrm{W}_{\mathrm{s}, 1}=\mathrm{W}_{\mathrm{p}, 1} \times \frac{\sigma_{1}}{1-\sigma_{1}}$

5-For $, \mathrm{i}=2,3, \ldots, \mathrm{n}:$ compute

$$
\begin{gathered}
\mathrm{W}_{\mathrm{b}, \mathrm{i}}=\mathrm{W}_{\mathrm{b}, \mathrm{i}-1}-\mathrm{W}_{\mathrm{p}, \mathrm{i}-1}-\mathrm{W}_{\mathrm{s}, \mathrm{i}-1} \\
\mathrm{~W}_{\mathrm{p}, \mathrm{i}}=\mathrm{W}_{\mathrm{b}, \mathrm{i}}\left(\mathrm{R}_{\mathrm{i}}-1\right) / \mathrm{R}_{\mathrm{i}} \\
\mathrm{W}_{\mathrm{s}, \mathrm{i}}=\mathrm{W}_{\mathrm{p}, \mathrm{i}} \times\left(\frac{\sigma_{\mathrm{i}}}{1-\sigma_{\mathrm{i}}}\right)
\end{gathered}
$$

end $i$

\section{End}

\section{Numerical example}

Determine the optimum performance of a three stage vehicle capable of placing of at least $400 \mathrm{Ib}$ into a 300 nautical mile, close circular, orbit .The initial assumptions are listed below:

\begin{tabular}{|l|c|c|c|}
\hline Stage & 1 & 2 & 3 \\
\hline Specific impulse $(\mathrm{sec})$ & 235 & 400 & 275 \\
\hline Payload, $\mathrm{W}_{\text {ap }}(\mathrm{Ib})$ & $\ldots \ldots \ldots \ldots$ & $\ldots \ldots \ldots \ldots \ldots$ & 400 \\
\hline Total velocity v(ft/esc) & $\ldots \ldots \ldots \ldots$ & $\ldots \ldots \ldots \ldots$ & 33750 \\
\hline Take-off weight(Ib) & 34750 & & \\
\hline Structure factor $\sigma$ & 0.07975 & 0.14718 & 0.12847 \\
\hline
\end{tabular}

\begin{tabular}{|c|c|c|}
\hline m & $\boldsymbol{\mu}$ & $\mathbf{F}(\boldsymbol{\mu})$ \\
\hline 1 & 0.00016300009245187374379 & 3144.14 \\
\hline 2 & 0.00017099471397889705110 & 338.498 \\
\hline 3 & 0.00017207299240852374188 & 4.64359 \\
\hline 4 & 0.00017208819830550760419 & 0.000893994 \\
\hline 5 & 0.00017208820123410756655 & $3.6379810^{11}$ \\
\hline 6 & 0.00017208820123410767497 & 0. \\
\hline 7 & 0.00017208820123410770208 & 0. \\
\hline 8 & 0.00017208820123410770208 & 0. \\
\hline
\end{tabular}

- Applying the above computational algorithm with $m=1,2, \ldots, 8$ and $\mathrm{Q}(\mu)=\mu-0.0002$ we find:

$\Delta$ Consider the value of $\mu$ for $m=7$, that is $\mu=0.00017208820123410770208$, we get : 

$\Delta \mathrm{R}_{1}=2.90989$
$\mathrm{R}_{2}=3.72902$
$\mathrm{R}_{3}=2.67583$
$\Delta \mathrm{W}_{\mathrm{s}, 1}=1976.57(\mathrm{Ib})$
$\mathrm{W}_{\mathrm{s}, 2}=1258.64(\mathrm{Ib})$
$\mathrm{W}_{\mathrm{s}, 3}=130.518(\mathrm{Ib})$
$\Delta \mathrm{W}_{\mathrm{p}, 1}=22808$.(Ib)
$\mathrm{W}_{\mathrm{p}, 2}=7293.06(\mathrm{Ib})$
$\mathrm{W}_{\mathrm{p}, 3}=885.42(\mathrm{Ib})$

In concluding the present paper, an iterative method of second order of convergence for optimum performance of multistage rockets is developed using homotopy continuation technique. The method does not need any priori knowledge of the initial guess, a property which avoids the critical situations between divergent to very slow convergent solutions, that may exist in the application of other numerical methods depending on initial guess.. The accuracy of the method is at least of $\mathrm{O}\left(10^{-20}\right)$,a sufficient accuracy that secures very accurate determination of the performance

\section{References}

Allgower, E.L. , and George , K. : 1990 , Numerical Continuation Methods, Springer Verlag, Berlin

Cornelisse,J.W. ,Schöyer,H.F.R.and Wakker,K.F.:(1979),Rocket Propulsion and Spaceflight Dynamics, Pitman Publishers,London.

Logsdon,T.:1998,Orbital Mechanics, Theory and Applications, John Wiley Sons ,Inc. New York.

Montenbruck,O.and Gill,E.:2000,Satellite Orbits, Models-Methods-Applications, Springer, Verlag, Berlin.

Sharaf,M.A.andSharaf,A.A.:2003,Celestial Mechanics and Dynamical Astronomy 86,351

Vallado,D:1997,Fundamentals of Astrodynamics and Applications ,The McGraw Hill Companies ,Inc.UAS

Received: December 3, 2005 